\title{
FEM Analysis on Concrete Columns Confined with CFRP Sheets by ANSYS
}

\author{
Kiran Malipatil and Tejas D. Doshi
}

\begin{abstract}
The use of carbon fiber-reinforced polymer CFRP composites for strengthening and/or rehabilitation of concrete structures is gaining increasing popularity in the civil engineering community. One of the most attractive applications of CFRP material is its use as confining devices for concrete columns, which may result in remarkable increases of strength and ductility as indicated by numerous published experimental results. Despite a large research effort, a proper analytical tool to predict the behavior of CFRP-confined concrete has not yet been established. This project presents the results of experimental and analytical study on the structural behavior of plain cement concrete column, reinforced cement concrete column and plain cement concrete column wrapped with carbon fiber reinforced polymer (CFRP) sheet.
\end{abstract}

Keywords--- CFRP, Column, ANSYS.

\section{INTRODUCTION}

$\mathrm{F}$ RP can be applied to strengthen the beams, columns and slabs of buildings and bridges. It is possible to increase the strength of structural members even after they have been severely damaged due to loading conditions. In the case of damaged reinforced concrete members, this would first require the repair of the member by removing loose debris and filling in cavities and cracks with mortar or epoxy resin. Once the member is repaired, strengthening can be achieved through wet, hand lay-up of impregnating the fiber sheets with epoxy resin then applying them to the cleaned and prepared surfaces of the member. Two techniques are typically adopted for the strengthening of beams, relating to the strength enhancement desired: flexural strengthening or shear strengthening. In many cases it may be necessary to provide both strength enhancements.

\section{OBJECTIVES OF THE STUDY}

The various objectives of our project are:

- To perform experimental investigation of the effect of carbon fiber reinforced polymer (CFRP) wrapping on the axial loaded column.

- To compare the performance of CFRP wrapped columns with the plain and steel reinforced cement concrete columns carrying axial load.

Kiran Malipatil, Assistant Professor, Dept. of Civil Engineering, KLE Dr. MSS College of Engineering and Technology, Belagavi, India. E-mail:malipatilkiran@gmail.com

Tejas D. Doshi, Assistant Professor, Dept. of Civil Engineering, KLE Dr. MSS College of Engineering and Technology, Belagavi, India. E-mail:tejas019@gmail.com

DOI:10.9756/BIJMMI.8182
- To carry out the analytical study, using ANSYS software of the plain concrete, reinforced concrete and CFRP wrapped concrete columns.

\section{GEOMETRY OF THE COLUMN}

In this project we casted totally three columns out of which, two were of plain cement concrete and one of reinforced cement concrete. Out of the two plain cement concrete column one column was confined with carbon fiber reinforced polymer (CFRP). After casting the cubes were kept for curing for 28 days.

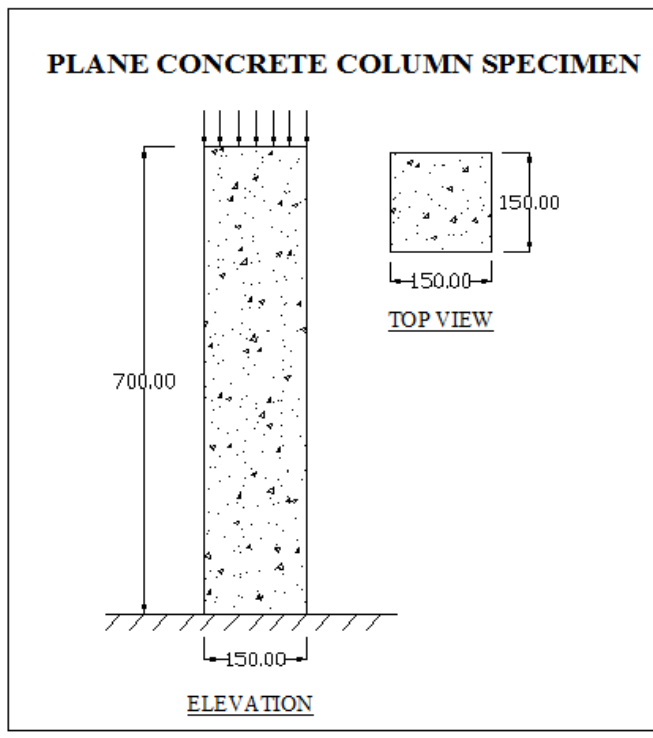

Figure 1: Column Specimen

\section{MATERIALS AND ITS PROPERTIES}

1) Cement

Table 1: Properties of Cement

\begin{tabular}{|l|l|}
\hline Description of Property & Values for Cement \\
\hline Specific Gravity & 3.15 \\
\hline Initial Setting Time & $65 \mathrm{~min}$ \\
\hline Final Setting Time & $520 \mathrm{~min}$ \\
\hline
\end{tabular}

2) Fine Aggregates

Table 2: Properties of Fine Aggregates

\begin{tabular}{|l|l|}
\hline Description of Property & Values for Fine Aggregate \\
\hline Specific Gravity & 2.52 \\
\hline Water Absorption & $1.3 \%$ \\
\hline
\end{tabular}




\section{3) Coarse Aggregates}

Table 3: Properties of Coarse Aggregates

\begin{tabular}{|l|l|}
\hline Description of Property & Values for Coarse Aggregate \\
\hline Specific Gravity & 2.82 \\
\hline Water Absorption & $0.8 \%$ \\
\hline
\end{tabular}

4) $C F R P$

Table 4: Properties of CFRP

\begin{tabular}{|l|l|}
\hline Name & 12KUD-300GSM \\
\hline Thickness & $0.167 \mathrm{~mm}$ \\
\hline \multirow{3}{*}{ Young 's Modulus } & Ex: $285000 \mathrm{MPa}$ \\
& $\mathrm{Ey}: 5400 \mathrm{MPa}$ \\
& $\mathrm{Ez}: 5400 \mathrm{MPa}$ \\
\hline \multirow{3}{*}{ Poisons ratio } & $\mu \mathrm{x}: 0.29$ \\
& $\mu \mathrm{y}: 0.43$ \\
& $\mu \mathrm{z}: 0.016$ \\
\hline Tensile strength & $\geq 3500 \mathrm{MPa}$ \\
\hline
\end{tabular}

\section{StRUCTURAL MODELING AND ANALYSIS}

\section{A. Elements Used for Modeling}

Various elements were used that describes the concrete, reinforcement, FRP sheets. SOLID 65 element was used to describe the concrete. SOLID 65 is eight nodded element with 3 degree of freedom in $\mathrm{x}, \mathrm{y}$ and $\mathrm{z}$ direction. The element that was used to describe the reinforcement was LINK 180 element and BEAM 188 element. BEAM 188 element is a linear, quadratic, or cubic two-node beam element. LINK 180 element is a 3-D spar two node element with three degree of freedom in $\mathrm{x}, \mathrm{y}$ and $\mathrm{z}$ direction. SOLID 186 was used to describe CFRP Sheet. The element is a higher order 3-D 20node solid element that exhibits quadratic displacement behavior.

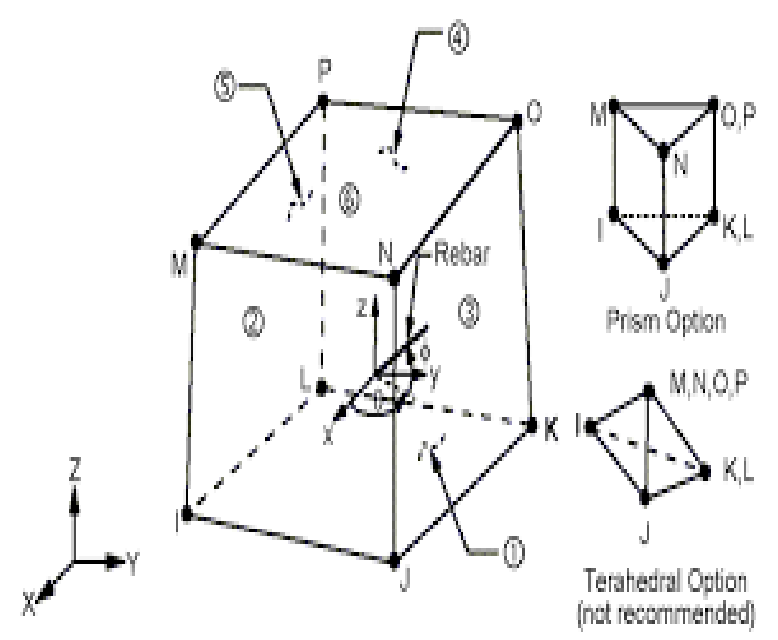

Figure 2: SOLID 65 Element

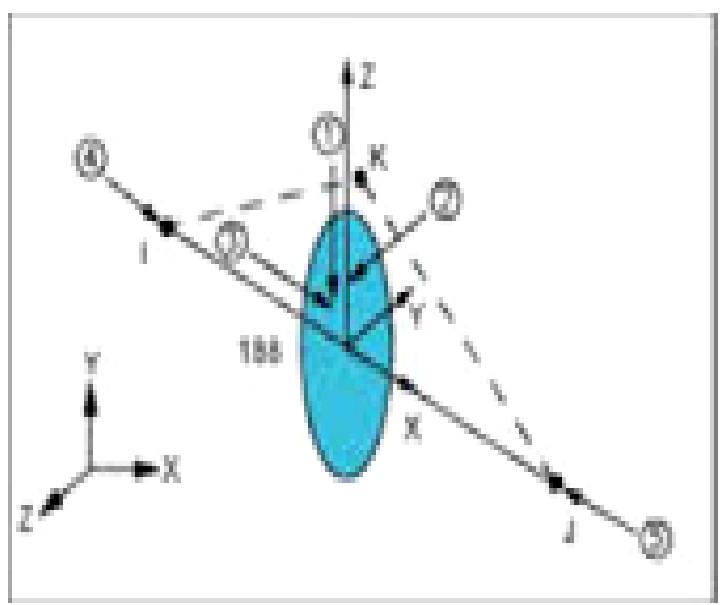

Figure 3: BEAM 188 Element

\section{B. Loading and Boundary Conditions}

The specimen is fixed at bottom and free at the top. At bottom in order to form fixed support $\mathrm{U}_{\mathrm{x}}, \mathrm{U}_{\mathrm{y}}$ and $\mathrm{U}_{\mathrm{z}}$ is given a constant value of 0 . Uniaxial load was applied at the top. The concentrated load was applied along the line such that the total load was divided with the number of elements along the line so as to distribute the loading along the line.

\section{RESULTS AND DISCUSSION}

Table 5: Comparison of Ultimate Load and Deformation by Experiment

\begin{tabular}{|l|l|l|l|}
\hline Specimen & PCC & RCC & CFRP \\
\hline Ultimate Load(kN) & 275 & 352 & 375 \\
\hline Deformation $(\mathrm{mm})$ & 9.08 & 10.3 & 7.2 \\
\hline
\end{tabular}

Table 6: Comparison of Ultimate Load and Deformation by ANSYS

\begin{tabular}{|l|l|l|l|}
\hline Specimen & PCC & RCC & CFRP \\
\hline Ultimate Load(kN) & 275 & 352 & 375 \\
\hline Deformation(mm) & 27.89 & 36.13 & 23.025 \\
\hline
\end{tabular}

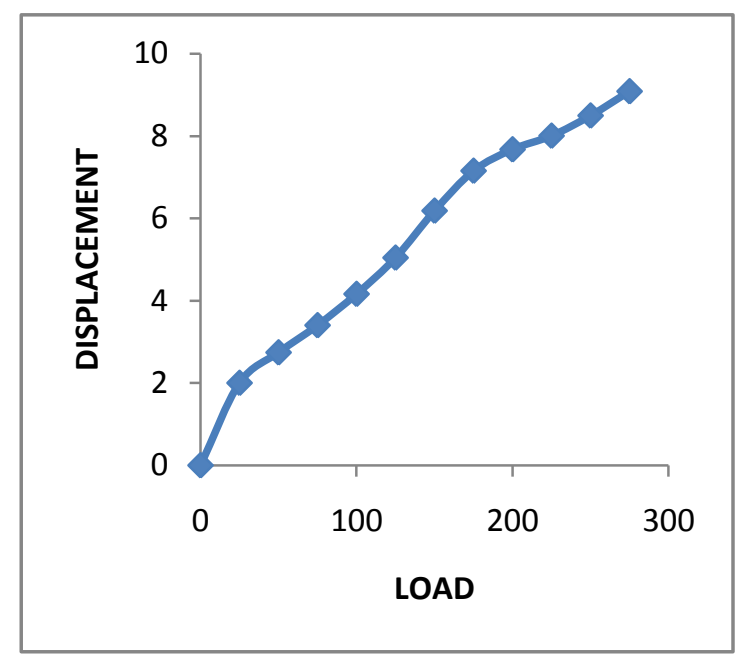

Figure 4: Displacement vs. Load Graph for PCC 


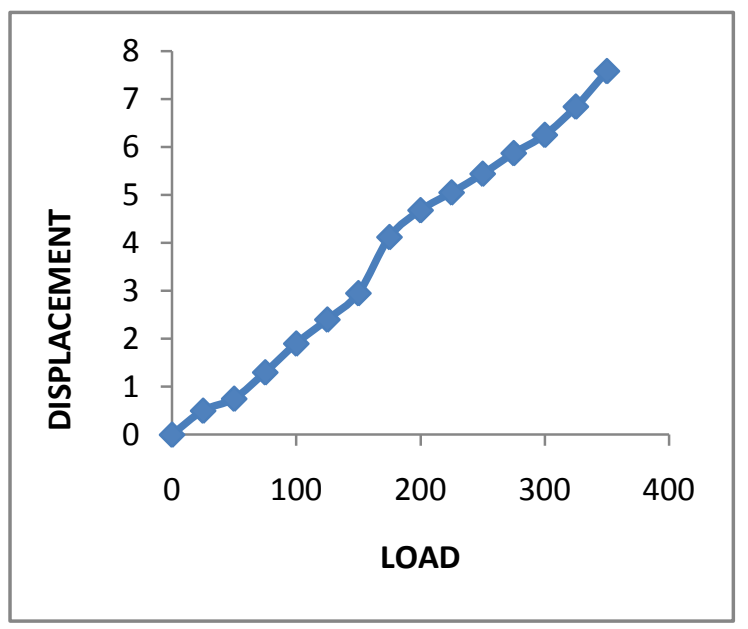

Figure 5: Displacement vs. Load Graph for RCC

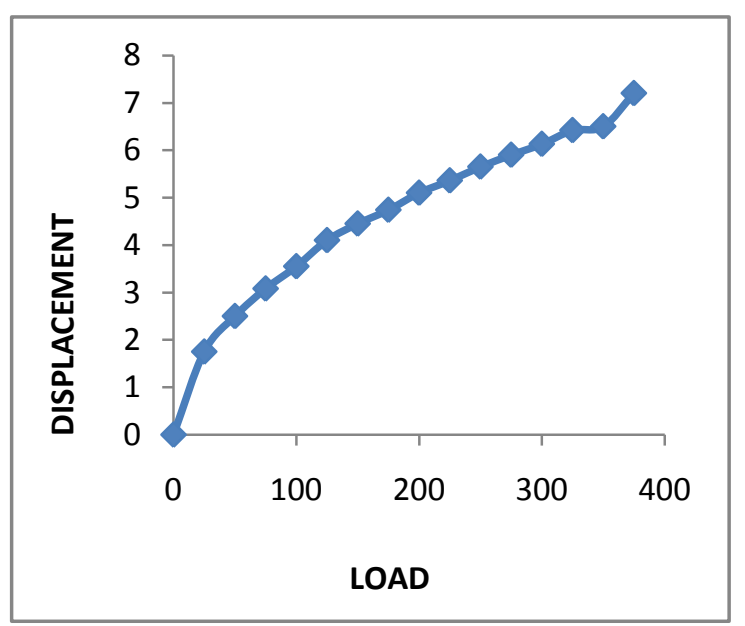

Figure 6: Displacement vs. Load Graph for CFRP Wrapped Column

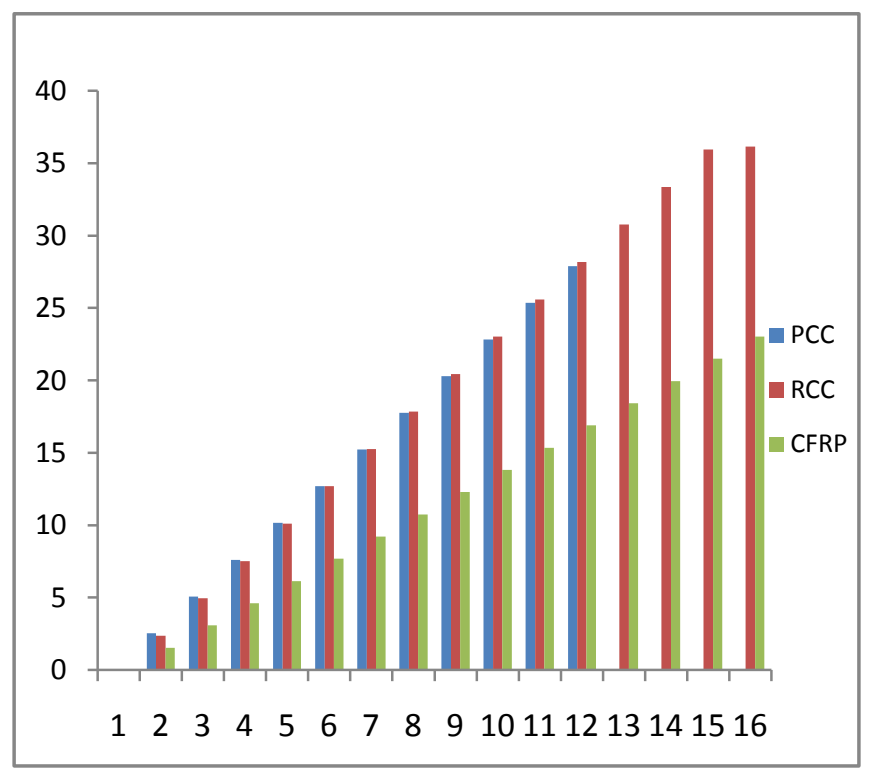

Figure 7: Comparison of Displacements for PCC, RCC and CFRP Columns

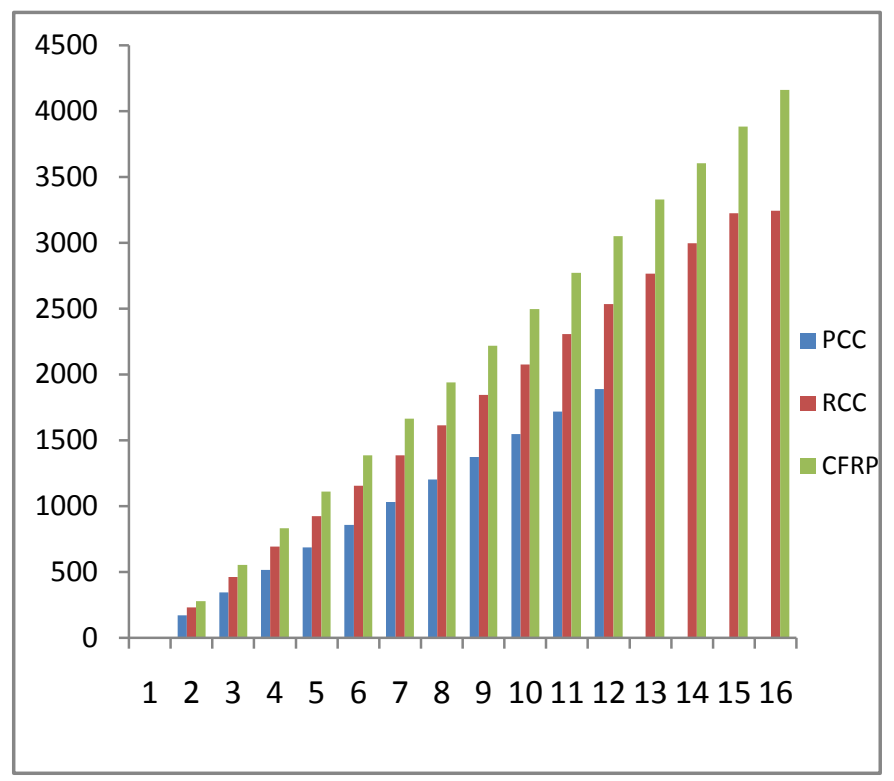

Figure 8: Comparison of Stress for PCC, RCC and CFRP Columns

\section{CONCLUSION}

The results of an experimental investigation on the performance of concrete square columns strengthened with CFRP material were presented in the previous chapter. Results indicate that the strength capacity of columns improved significantly as a result of the action of the transverse weaves of the composite fabric. The following conclusions can be drawn from the present study.

- The CFRP composites improved the uniaxial capacity of the columns. The maximum gain achieved was $36.36 \%$ for CFRP specimen. The gain in the strength is nearly 1.1 times that of steel reinforced concrete column.

- The CFRP wrapped column is stiff and rigid since percentage variation in displacement for CFRP wrapped columns is less when compared to that of plain cement concrete column and reinforced cement concrete column by both experimental and software.

- Percentage variation in stress for CFRP wrapped columns is less when compared to that of plain cement concrete column and reinforced cement column.

- Although CFRP sheet is costly, we can reduce the dead load of the column to greater extent by replacing reinforcement with CFRP sheets.

- In software in order to create reinforcement we used both beam element and link element. The results obtained from both the elements were almost same.

- FEA package ANSYS can give variety of results and can handle all types of problems. 


\section{REFERENCES}

[1]. A. Mirmiran, M. Shahawy, M. Samaan, H.E. Echary, J.C. Mastrapa and O. Pico, "Effect of column parameters on FRP-confined concrete. Journal of Composites for Construction, Vol. 2, No. 4, Pp. 175-185, 1998.

[2]. A. Mirmiran and M. Shahawy, "Behavior of concrete columns confined by fiber composites. Journal of Structural Engineering, Vol. 123, No. 5, Pp. 583-590, 1997.

[3]. I.A.E.M. Shehata, L.A.V. Carneiro and L.C.D. Shehata, "Strength of short concrete columns confined with CFRP sheets", Materials and Structures, Vol. 35,_No. 1, Pp. 50-58, 2002.

[4]. M. Demers and K.W. Neale, "Confinement of reinforced concrete columns with fiber-reinforced composite sheets-an experimental study", Canadian Journal of Civil Engineering, Vol. 26, No. 2, Pp. 226-241, 1999.

[5]. A. Chakrabarti, A. Chandra and Bharagava, "Finite Element Analysis of Concrete Columns Confined with FRP Sheets", Journal of Reinforced Plastics and Composites, Vol. 27, Pp. 1349-1373, 2008. 